\title{
Redução da Taxa de Queda de Chamada em Rede Celular GSM por Meio de Ajustes dos Parâmetros de Cobertura
}

\author{
Gabriel F. Pivaro e Amílcar C. César
}

\begin{abstract}
Resumo - Neste artigo é realizado um estudo sobre as causas principais de quedas de chamada em uma célula de rede celular GSM operando em $900 \mathrm{MHz}$. Por meio de análise de dados de tráfego das estações rádio base (ERB) verifica-se que a maioria das quedas ocorre devido ao baixo nível de sinal na interface aérea e à queda repentina de conexão entre a estação móvel (EM) e a ERB. Com base nesses dados, ajuste de alguns dos parâmetros de cobertura é efetuado, reduzindo a taxa de quedas de chamadas em uma célula, sem a necessidade de alterações físicas na ERB e sem deteriorar outros indicadores de qualidade.
\end{abstract}

Palavras-chave - comunicação móvel celular, retenção de chamadas, taxa de quedas de chamada, desempenho, GSM, qualidade do serviço.

Abstract - This paper analyses the main causes of dropped calls in cellular GSM network cell operating in $900 \mathrm{MHz}$. The approach is based on traffic cell data collected by statistics management software running on cellular system. Data analysis obtained from a number of cells has shown that low signal strength and sudden loss of connection are the main causes of the dropped calls. Based on data analysis we proposed adjusts in the coverage parameters cell to obtain a reduction of the call drop rate in a cell without changing equipments of the BTS and without causing bad quality in others indicators.

Keywords - mobile cellular systems, retainability, call drop rate, performance indicators, GSM, quality of service.

\section{INTRODUÇÃO}

Os sistemas de comunicações móveis celulares que utilizam tecnologia GSM (global system for mobile communication) estão em plena expansão no Brasil. As redes das operadoras celulares estão sendo ampliadas tanto em capacidade (implantação de novos equipamentos para atender a demanda do crescente número de assinantes) como em cobertura (novas cidades ou regiões).

Ao mesmo tempo em que essa expansão ocorre, as operadoras precisam estar atentas ao desempenho dessas redes, principalmente o da interface aérea, que interliga a EM

Gabriel F. Pivaro, Amílcar C. César, Universidade de São Paulo, Escola de Engenharia de São Carlos, Depto. Eng. Elétrica, São Carlos, SP. E-mails: gconceicao@hotmail.com; amilcar@sel.eesc.usp.br. e a ERB. Um bom desempenho dessa interface é importante para maximizar o retorno do investimento em equipamentos, aumentar a capacidade da rede e garantir que o assinante esteja satisfeito com a qualidade do serviço (quality of service-QoS) oferecido [1]-[3].

As operadoras necessitam de ferramentas capazes de coletar dados sobre a utilização da rede e a definição das métricas que serão utilizadas para definir e monitorar o desempenho da rede [1], [3]. O desempenho de uma rede celular oferecendo serviços de voz pode ser monitorado por meio de ferramentas de coletada de dados. Essas ferramentas permitem realizar diversas medições, como o número de chamadas realizadas com sucesso, número de chamadas bloqueadas devido a congestionamento, número de quedas de chamada (QC). As ferramentas mais utilizadas nesses casos são o gerenciamento estatístico (GE) e o drive test (DT) [1], [3]. O GE é responsável pela coleta de dados de situação de chamadas por meio dos contadores que podem ser ativados na controladora das estações rádio base (BSC-base station controller), fornecendo visão ampla da operação de toda a rede celular. Já o DT utiliza EM conectadas a computadores pessoais para efetuar uma série de chamadas de teste em uma área, sendo utilizado mais especificamente em testes após o início de operação ou alteração em uma ERB.

Exemplo de métrica são os eventos monitorados na rede a fim de observar se um determinado desempenho está sendo alcançado [1]-[4]. A queda de chamada (QC) é um dos mais importantes indicadores de QoS. A QC implica em reflexos diretos na percepção de QoS que o assinante possui da rede. Uma das causas de ocorrência de QC é degradação da qualidade do sinal na interface aérea [5].

Em relação à comunicação entre EM e ERB em redes GSM, boa parte das abordagens utilizam simuladores de comportamento dos assinantes em uma área coberta por diversas ERB [4]-[6]. Por outro lado, alguns trabalhos utilizam redes em operação para coleta e alteração de parâmetros para reduzir as QC [2], [3], [7], [8].

As abordagens que tratam de melhorias e aperfeiçoamentos na interface aérea podem ser divididas em [1], [2], [4]-[8]: desenvolvimento de equipamentos, como antenas, filtros, combinadores, diversidades de recepção; técnicas de acesso, como frequency hopping-FH, fractional loading-FL, transmissão descontínua-DTX, reuso de freqüências, esquemas de alocação de canais e restabelecimento de 
chamada; alteração na padronização (evolução de algoritmos) e alteração de parâmetros da rede.

O objetivo deste trabalho é analisar as causas de QC com base em coleta e análise de dados estatísticos de rede GSM e implementar técnica de redução da taxa de queda de chamada (TQC) por meio do ajuste de parâmetros de cobertura. A partir da identificação das causas principais de QC será possível determinar quais parâmetros podem ser alterados. O desempenho da rede é avaliado depois que as alterações forem realizadas.

Uma das principais vantagens da técnica de redução da TQC por meio do ajuste de parâmetros de cobertura é evitar custos operacionais com a instalação de novos equipamentos e deslocamentos de pessoal técnico.

Os dados de tráfego da operadora de rede celular GSM foram obtidos durante 2006 e 2007, de uma BSC Ericsson controlando 158 células da região noroeste do estado de São Paulo, que cobrem uma cidade de porte médio e cidades vizinhas menores, incluindo rodovias de interligação. A célula estudada opera em 909,6 MHz no uplink e 954,6 MHz no downlink.

O artigo está organizado da seguinte forma: na Seção II, serão apresentados os indicadores de desempenho. A Seção III mostra o algoritmo de localização e alguns de seus parâmetros responsáveis pela configuração de cobertura da rede. Os algoritmos de desconexão de chamada são apresentados na Seção IV. A análise estatística das causas de quedas e os resultados obtidos com os ajustes dos parâmetros são mostrados na Seção V. As conclusões deste trabalho estão na Seção VI.

\section{INDICADORES DE DESEMPENHO DA REDE}

Os principais indicadores de desempenho (key performance indicator-KPI) são [1], [2]: capacidade de acesso do assinante à rede (acessibilidade); capacidade de manter chamada sem que haja QC (retenção); e qualidade de chamada (integridade).

A acessibilidade trata da capacidade da rede em atender uma solicitação de acesso de um assinante, que pode ser uma chamada de voz ou envio de uma mensagem de texto. A acessibilidade monitora os eventos desde a chegada dessa solicitação até a alocação de um canal de voz [1]. A disponibilidade de canais, a porcentagem de tentativas de acesso com sucesso e o congestionamento são exemplos de estatísticas de acessibilidade [2].

$\mathrm{O}$ indicador de integridade gerencia a qualidade das chamadas. No caso de chamadas de voz, ele é responsável por mostrar se a qualidade de uma chamada é boa, aceitável ou ruim em termos de taxa de erro de bit (bit error rate$\mathrm{BER}$ ) e taxa de apagamento de quadro (frame erasure rateFER) [1], [5], [7].

A retenção é responsável por monitorar o desempenho de uma chamada desde o instante da alocação do canal até o encerramento [1]. O gerenciamento estatístico trata da TQC e dos handovers perdidos.

Manter um número baixo de QC é uma das estratégias para garantir QoS [1]-[3]. A QC ocorre toda vez que a chamada é prematuramente interrompida, isto é, quando o assinante não solicita o encerramento da chamada.

A TQC mede a porcentagem de QC ocorridas durante a ocupação dos canais de voz. Existem vários métodos para determinar a TQC, como a relação entre quedas e total de chamadas originadas ou entre quedas e total de chamadas administradas por cada célula, incluindo os handovers [1], [5].

Neste artigo, a TQC é a relação entre o número total de quedas e o número total de alocações em canais de voz. As alocações podem ser por primeira tentativa de realizar a chamada ou por handovers. O valor limite utilizado como referência para a TQC é 2\% [1], [5].

Com base em dados estatísticos obtidos por meio do GE, as causas principais de QC em rede GSM serão investigadas. Em seguida, uma célula será escolhida para estudo detalhado visando à redução da TQC.

\section{ALGORITMO DE LOCALIZAÇÃO}

A rede celular de uma operadora deve ser capaz de reter uma chamada telefônica enquanto o assinante desejar, estando ele imóvel ou se deslocando. Como as células possuem uma área de cobertura restrita (alguns quilômetros de raio), o controle da chamada deve ser trocado de uma célula para outra, ou por causa do deslocamento do assinante ou por causa do nível de sinal recebido. Essa troca é o handover, sendo a ferramenta utilizada pelo algoritmo de localização (AL) para manter a chamada até que o assinante resolva encerrá-la. O critério principal para a escolha da melhor célula para a EM estar é baseado na medição do nível de sinal recebido pela EM (SS—signal strength) [5], [9], [10].

O AL funciona da seguinte forma: enquanto a EM está no modo ativo (em chamada), a BSC envia uma lista contendo a freqüência do canal de controle (BCCH) das células que estão próximas à célula em que a EM está (célula servidora-CS), chamada BCCH allocation list (BA list). A EM efetua a medição do SS dessas freqüências e do SS e BER recebidos da CS. Essas medições são enviadas à ERB, que anexa as suas medições referentes àquela $\mathrm{EM}$, de SS, BER e o tempo de propagação das rajadas entre EM e ERB (TA-time advance, ver Seção IV). A ERB então envia estes dados à BSC. Estas trocas de sinalização na interface aérea utilizam o canal de controle associado lento (SACCH—slow associated control channel). Suas funções são transportar as ordens de alterações à EM (downlink) e as medições efetuadas pela EM (uplink) [1], [5].

A partir destas informações o AL elabora uma lista de células candidatas ao handover. A elaboração da lista inclui ainda parâmetros de cobertura, como SS mínimo e máxima potência de saída permitida para EM e ERB, definidos pelo responsável da rede [10]. Esses parâmetros servem para controlar o comportamento da EM enquanto estiver sob a cobertura de uma célula [6]. Dois parâmetros importantes para o controle de cobertura são a histerese e o offset [4], [10].

O efeito do offset é criar uma borda nominal deslocada da borda original da cobertura da célula definida pelo nível de sinal recebido. O offset pode ser positivo ou negativo. Caso 
seja positivo, o deslocamento da borda reduz a área de cobertura e, dessa forma, posiciona a célula em uma colocação inferior na lista de handover. Já no caso de offset negativo, a borda da célula é expandida, melhorando a colocação na lista de handover [10].

A histerese é utilizada para criar uma área em torno da borda nominal da célula, chamada corredor de histerese [4], [10]. Nessa área, a chamada prossegue, sendo controlada pela célula na qual a EM estava. A histerese serve para evitar que a EM faça o handover e, logo em seguida, volte para a célula antiga. Esse efeito ping-pong [1], [4] ocorre devido às flutuações sofridas pelo sinal em uma área em que o SS recebido pela EM proveniente de duas células é bastante próximo. A histerese é subtraída do SS das células vizinhas, privilegiando o nível da CS. Dessa forma, o handover só ocorrerá quando o SS de uma célula vizinha for razoavelmente maior do que o da CS.

O AL cria a lista de candidatos a cada 0,48 s. Geralmente, o AL irá sugerir que a EM permaneça na mesma célula. Caso contrário, a BSC ordenará que a EM sintonize na freqüência da célula mais bem colocada na lista, iniciando o handover.

Desse modo, o AL tem como objetivo manter a EM naquela célula em que existam as melhores condições para que a chamada seja mantida. Caso as medições fornecidas ao AL indiquem que as condições da interface aérea não podem ser melhoradas com o aumento da potência ou com a execução de um handover, o processo de desconexão dessa chamada será iniciado, gerando a QC.

A seguir, três mecanismos responsáveis por desconectar uma chamada serão descritos.

\section{Algoritmos de DesconeXão de Chamadas}

O primeiro mecanismo desconecta uma chamada quando a distância entre a EM e ERB ultrapassa o valor permitido para que o sinal transmitido pela EM alcance a ERB [1], [10]. Isso ocorre porque a ERB disponibiliza, em cada uma de suas portadoras, um intervalo de tempo (time slot-TS) para o recebimento do sinal da EM. Cada TS é igual a $577 \mu$ s e transporta 148 bits de informação. De acordo com o padrão GSM [1], é permitido que a EM transmita sua rajada antecipando-a em TA equivalente a 63 bits para que, devido ao tempo de propagação do sinal na interface aérea, ela alcance a ERB dentro do TS designado. Sem a antecipação, a rajada transmitida por essa EM interferirá na recepção das informações enviadas por outra EM. Nesse caso, o algoritmo de localização calcula a atraso na propagação entre a EM e a ERB. Se o valor for maior do que 63, um handover será recomendado [10]. Se não houver possibilidade de handover, por falta de células candidatas, então a chamada será desconectada e a causa associada à QC será “distância excessiva”. O TA de 63 bits permite uma distância máxima de $35 \mathrm{~km} \mathrm{[10],} \mathrm{[11].}$

O segundo mecanismo de desconexão é responsável pelo término das chamadas para quais as mensagens de controle não são corretamente decodificadas devido à relação sinalruído ou SS baixos. Assim, durante uma chamada são trocadas mensagens de sinalização e controle entre a EM e a ERB por meio do SACCH.

Esse algoritmo de desconexão atua da seguinte forma: o contador adiciona duas unidades para cada mensagem enviada por meio do SACCH e decodificada com sucesso, e subtrai uma unidade para cada falha na decodificação [5], [10]. O valor máximo do contador é definido pelo parâmetro RADIO LINK TIMEOUT, escolhido pelo responsável da rede. Caso o contador atinja o valor zero, então a chamada será desconectada e o contador de QC será incrementado com a condição de urgência de "baixo nível de sinal” ou de "baixa qualidade”, apresentada no momento da desconexão.

Um terceiro mecanismo atua na execução do handover. Esse mecanismo utiliza timers para determinar se há necessidade de desconectar uma EM que recebeu ordem para efetuar o handover, não obteve sucesso e também não conseguiu voltar para o canal antigo [10]. Neste caso, a QC é por perda repentina.

Portanto, ao se analisar uma QC ocorrida na interface aérea, deve-se identificar qual dos três mecanismos foi o responsável pela desconexão e qual a condição (baixo SS, BER/FER ou distância excessiva) que a conexão entre ERB e EM apresentava.

\section{V.ANÁLISE E RESULTADOS}

\section{A. Identificação das causas principais de queda de chamadas}

A Fig. 1 mostra a distribuição das causas de todas as QC ocorridas na BSC durante o período de um ano. Com base nos dados do GE é possível fazer a distribuição percentual de QC por motivo de queda: quedas por distância excessiva (QDE); quedas por perda repentina (QPR); quedas por baixo nível de sinal (QSx, $\mathrm{x}=\mathrm{B}$, uplink e downlink simultaneamente; $\mathrm{x}=\mathrm{U}$, uplink; $\mathrm{x}=\mathrm{D}$, downlink); quedas por baixa qualidade (QQX); outras causas (QOC). As duas principais causas de QC são QPR e QSB que somam mais de $50 \%$ de todas as QC.

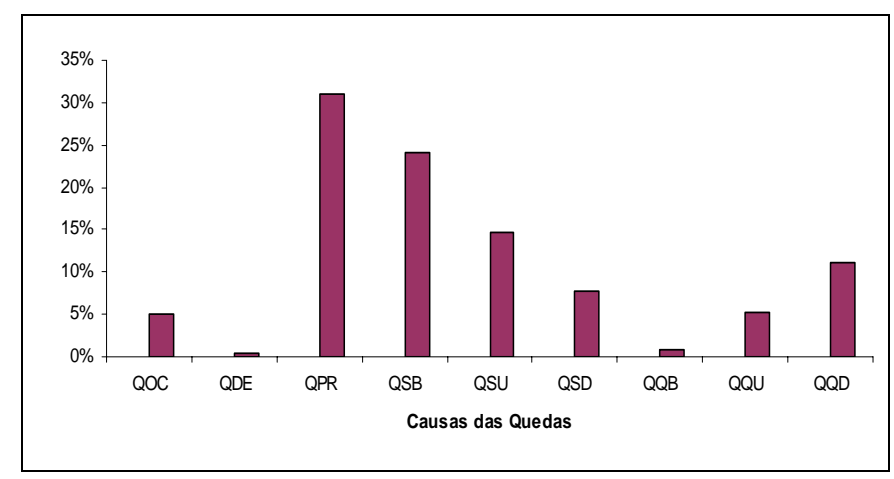

Fig. 1. Causas de QC em uma BSC com 158 células de operadora GSM durante o ano de 2006. As duas principais causas são QPR e QSB.

As QPRs ocorrem principalmente por perda de comunicação entre a EM e a ERB causada por: falha em elemento da rede, comportamento dos assinantes, parâmetros de cobertura incorretos ou por erro de decodificação de dados [1], [5]. Mostraremos nesta seção que a redução do número 
de handovers perdidos é importante fator para reduzir a QPR e, conseqüentemente, a TQC.

A Fig. 2 mostra a relação entre a cobertura média das células, QPR e TQC. As células com maior TQC apresentam uma cobertura média em quilômetros maior do que a das células com TQC mais baixa. Por outro lado, à medida que a TQC diminui, a QPR têm impacto maior na porcentagem total de quedas.

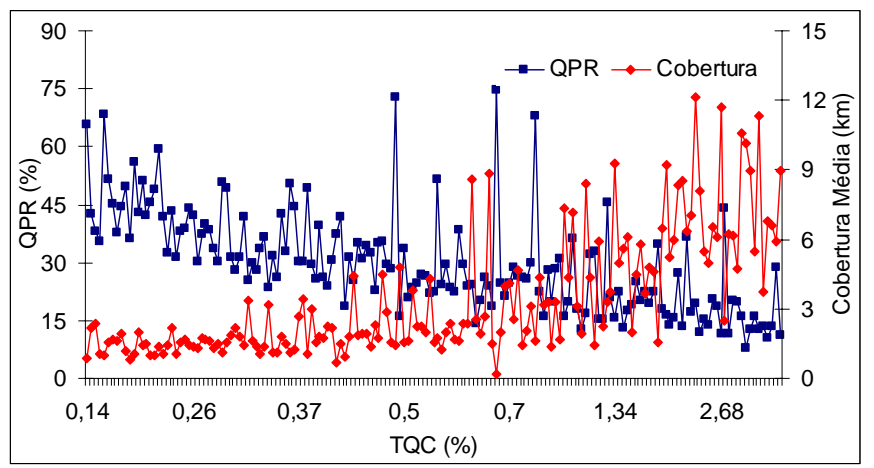

Fig. 2. Relação entre cobertura média das células, QPR e TQC. Células com cobertura mais extensa apresentam maior TQC. Células com menor TQC apresentam QPR como maior causa de QC.

Concluímos que, em células que cobrem regiões urbanas, cobertura mais restrita, a porcentagem de QPR é muito maior do que de QSx. Isso ocorre porque em áreas urbanas existem muitas células vizinhas que acabam por sobrepor suas coberturas, o que permite maior nível de sinal na interface aérea. Entretanto, em células com coberturas mais extensas, tipicamente as de rodovias, o sinal sofre maior degradação, acarretando maior TQC devido ao baixo SS.

\section{B. Escolha de uma célula para análise}

Analisar as causas de QC em todas as células da BSC é tarefa complexa devido à natureza e variação temporal. Por esse motivo, escolhemos uma das 158 células para análise. É uma célula de rodovia, com cobertura média de 7,23 km, daqui em diante denominada célula $\mathrm{A}$. Esta célula reúne parâmetros físicos otimizados para configuração de melhor eficiência. A ERB dessa célula utiliza: cabo com bitola 1 5/8 polegada, que possui a menor perda entre os disponíveis; amplificadores montados na torre, que amplificam o sinal recebido, proporcionando maior área de cobertura para a célula; freqüência portadora na faixa de $900 \mathrm{MHz}$, proporcionando menor atenuação; diversidade de espaço nas antenas de recepção; combinação de dois transmissores para dobrar a potência de transmissão no downlink. Portanto, os parâmetros de cobertura serão ajustados para reduzir a TQC.

De acordo com a Fig. 2, a causa de QC neste tipo de célula ocorre, primordialmente, devido à QSx na interface aérea. Porém, essa célula apresenta 46,54\% de QPR, como mostra a Tabela 1.

TABELA 1. CAUSAS DE QC DA CÉLULA A.

\begin{tabular}{|c|c|c|c|c|c|c|c|c|}
\hline $\begin{array}{c}\text { QSB } \\
(\%)\end{array}$ & $\begin{array}{c}\text { QSU } \\
(\%)\end{array}$ & $\begin{array}{c}\text { QSD } \\
(\%)\end{array}$ & $\begin{array}{c}\text { QQB } \\
(\%)\end{array}$ & $\begin{array}{c}\text { QQU } \\
(\%)\end{array}$ & $\begin{array}{c}\text { QQD } \\
(\%)\end{array}$ & $\begin{array}{c}\text { QDE } \\
(\%)\end{array}$ & $\begin{array}{c}\text { QPR } \\
(\%)\end{array}$ & $\begin{array}{c}\text { QOC } \\
(\%)\end{array}$ \\
\hline 14,94 & 24,95 & 2,03 & 0,13 & 0,47 & 10,03 & 0,03 & 46,54 & 0,88 \\
\hline
\end{tabular}

\section{C.Alteração dos parâmetros de cobertura}

A seguir, são apresentadas as alterações que foram analisadas e implementadas para reduzir a TQC.

1. Alteração do mínimo nível de sinal para acampar na célula (ACCMIN_minimum received signal level at the EM required for accessing the system): Com a alteração do ACCMIN [10] de $-102 \mathrm{dBm}$ para $-96 \mathrm{dBm}$, a EM necessitaria estar mais próxima da ERB (menor atenuação de percurso) para se registrar na rede. As EM que estivessem na área de cobertura da célula com SS menor do que $-96 \mathrm{dBm}$ não poderiam acampar nessa célula. Com essa alteração a TQC passou de $8,96 \%$ para 5,81\% de junho a julho de 2006 . O valor do ACCMIN não interfere na execução do handover, isto é, as EMs que estão em chamada e possuem SS menor do que este parâmetro podem efetuar o handover para esta célula.

2. Exclusão de vizinhança: Conforme mostra a Fig. 2, a causa mais freqüente de QC em células de rodovia (cobertura extensa) não é a QPR. Contudo, a célula A indica a QPR como maior causadora de QC (Tabela 1), motivando análise da relação de handover com as células vizinhas. A Tabela 2 apresenta o desempenho geral dos handovers desta célula, onde se verificou que havia uma perda de 30,12\% nos handovers de saída. Em direção à célula $\mathrm{B}$ (célula cobrindo cidade próxima da rodovia e vizinha a célula A), a perda era superior a $90 \%$. Devido a problemas de invasão de sinal em área de outra operadora, uma restrição na cobertura da célula B por meio da redução do TA de $63(35 \mathrm{~km})$ para $5(2,5 \mathrm{~km})$ estava ativa. Assim, quando uma EM recebia ordem de efetuar o handover da célula A para célula B, a ERB de B calculava o valor do TA, que quase sempre era maior do que 5, e não permitia a conclusão do handover. Em conseqüência, ocorria QC, que era contabilizada para a célula de origem, nesse caso a célula A. A exclusão dessa relação de vizinhança ocasionou uma redução da TQC de 5,19\% para 2,27\% de janeiro para fevereiro de 2007. As QPR passaram de 49,91\% para 23,1\% e os handovers de saída perdidos passaram de $30,12 \%$ para $2,42 \%$.

TABELA 2. DESEMPENHO DOS HANDOVERS DA CÉLULA A.

\begin{tabular}{|c|c|c|c|c|c|}
\hline \multicolumn{3}{|c|}{ Handovers saída } & \multicolumn{3}{c|}{ Handovers entrada } \\
\hline $\begin{array}{c}\text { Sucesso } \\
(\%)\end{array}$ & $\begin{array}{c}\text { Reversos } \\
(\%)\end{array}$ & $\begin{array}{c}\text { Perdidos } \\
(\%)\end{array}$ & $\begin{array}{c}\text { Sucesso } \\
(\%)\end{array}$ & $\begin{array}{c}\text { Reversos } \\
(\%)\end{array}$ & $\begin{array}{c}\text { Perdidos } \\
(\%)\end{array}$ \\
\hline 61,09 & 8,79 & 30,12 & 93,62 & 5,24 & 1,14 \\
\hline
\end{tabular}

3. Acréscimo de vizinhança: Uma ferramenta potente de análise de relações de vizinhança entre células são as medições de SS e BER efetuadas pelas EM durante uma chamada. É possível inserir freqüências de teste na $B A$ list para descobrir se células próximas da célula $A$ podem ser acrescentadas como vizinhas de A [6]. Um estudo da região geográfica no entorno da célula A permitiu verificar que algumas freqüências de células que estavam próximas poderiam ser inseridas na BA list das EM que estavam em chamada nessa célula. Com esses dados e utilizando o algoritmo de otimização de vizinhança da Ericsson [1], [10], 
foi possível determinar que uma célula que estava próxima da célula A e que não possuía relação de vizinhança com essa célula poderia ser acrescentada. A célula C (cobertura de cidade próxima a rodovia) foi acrescentada em 15 de agosto de 2007. O desempenho um mês após o acréscimo da célula $\mathrm{C}$ foi o seguinte: a porcentagem de tentativas de handover da célula A para célula C foi $18 \%$, correspondendo a 2.667 tentativas. Dessas tentativas, $77,24 \%$ foram com sucesso, $22,16 \%$ reversas (ocorreu handover, porém logo em seguida a chamada retornou à célula anterior) e apenas $0,6 \%$ foram perdidas. A porcentagem total de handovers perdidos caiu de $2,44 \%$ para $1,48 \%$, significando que a alteração causou um efeito positivo no desempenho dos handovers de saída. No desempenho global de handovers (entrada e saída) também houve redução nas perdas de 1,59\% para 1,04\%. Já a TQC nesse período passou de 1,9\% para 1,5\%.

4. Alteração do controle automático de potência: Após a última alteração, o valor da TQC já estava abaixo do valor padrão de $2 \%$ adotado para este indicador. A partir dessa constatação, poderíamos encerrar as atividades nessa célula e voltar atenção para as células com TQC acima de $2 \%$. Entretanto, continuamos investigando as causas desse 1,5\% de QC para mostrar que existem outros indicadores importantes para análise do desempenho de uma célula. Entre esses indicadores está o comportamento do sinal que trafega pela interface aérea e que pode ser estudado sem o auxílio de equipamentos específicos de medição de sinais.

Após a alteração anterior, as principais causas de QC apresentam as seguintes porcentagens: QPR (19,7\%), QSB (31,5\%), QSU (30,4\%) e QSD (3,21\%). As QCs ocorrem em $30,4 \%$ por baixo SS no uplink e apenas 3,21\% por baixo SS no downlink. Seria razoável supor que das QC devido ao baixo SS quase todas deveriam ser em ambas as direções, uma vez que a atenuação de percurso do sinal deveria ser igual em ambos os sentidos. Com base nessas observações, vamos analisar a interface aérea.

As medições efetuadas pela ERB e EM durante as chamadas controladas pela célula A apresentam comportamento da interface aérea mostrado na Tabela 3. As colunas apresentam as seguintes informações: porcentagem de rajadas recebidas com SS menor do que $-94 \mathrm{dBm}$ no uplink (SS UP) e no downlink (SS DL); e atenuação de percurso média (PLAVG); porcentagem de rajadas recebidas com qualidade de recepção (RXQUAL) acima de 3 (4 a 7, qualidade aceitável e ruim).

TABELA 3. COMPORTAMENTO DO SINAL NA INTERFACE AÉREA DA CÉLULA A.

\begin{tabular}{|c|c|c|c|c|c|}
\hline $\begin{array}{c}\text { SS UP } \\
<-94 \mathrm{dBm} \\
(\%)\end{array}$ & $\begin{array}{c}\text { SS DL } \\
<-94 \mathrm{dBm} \\
(\%)\end{array}$ & $\begin{array}{c}\text { PLAVG } \\
\text { UP } \\
(\mathrm{dB})\end{array}$ & $\begin{array}{c}\text { PLAVG } \\
\text { DL } \\
(\mathrm{dB})\end{array}$ & $\begin{array}{c}\text { RXQUAL } \\
\text { UP } \\
>3(\%)\end{array}$ & $\begin{array}{c}\text { RXQUAL } \\
\text { DL } \\
>3(\%)\end{array}$ \\
\hline 69,56 & 26,85 & 125,48 & 128,48 & 8,39 & 5,7 \\
\hline
\end{tabular}

Por meio da Tabela 3 verifica-se que, na célula estudada, $69,56 \%$ das rajadas recebidas no uplink apresentaram SS inferior a $-94 \mathrm{dBm}$, enquanto no downlink esse valor é 26,85\%. A atenuação média no percurso uplink é 125,48 dB e no downlink é 128,48 dB, ou seja, há $3 \mathrm{~dB}$ de diferença entre os sinais downlink e uplink. Nota-se que apesar da atenuação no uplink ser menor a porcentagem de rajadas recebidas com baixo nível é 2,6 vezes maior do que no downlink.

A partir desses resultados concluímos que a única solução para aumentar o nível do sinal recebido no uplink é aumentar a potência de transmissão das EM. Entretanto, a potência permitida para transmissão das EM já está no valor máximo, $33 \mathrm{dBm}$. Como a função controle automático de potência (PC-power control) está ativa nos dois sentidos, a EM não transmite o tempo todo com a máxima potência, mas sim com a potência estabelecida pela BSC por meio das medições (Seção III). O PC funciona da seguinte maneira: a BSC se baseia em um nível de referência (NR), que será comparado com o nível SS recebido; a potência da EM será regulada de tal forma que o nível recebido na ERB seja o NR. Foi verificado que o NR definido para aquela célula era $-95 \mathrm{dBm}$. Para aproximar o valor médio das medições no uplink com as do downlink, foi sugerida a alteração desse valor de referência para $-82 \mathrm{dBm}$, forçando as EM a operarem com potência de transmissão um pouco maior durante maior número de rajadas. Essa alteração foi implementada no dia 15 de setembro de 2007 e permaneceu até o dia 30 do mesmo mês. A Fig. 3 compara os níveis recebidos no uplink entre três ajustes: com $N R=-95 \mathrm{dBm} ; N R=-82 \mathrm{dBm}$ e com potência máxima, ou seja, sem o PC (em operação entre 1 e 15 de novembro de 2007).

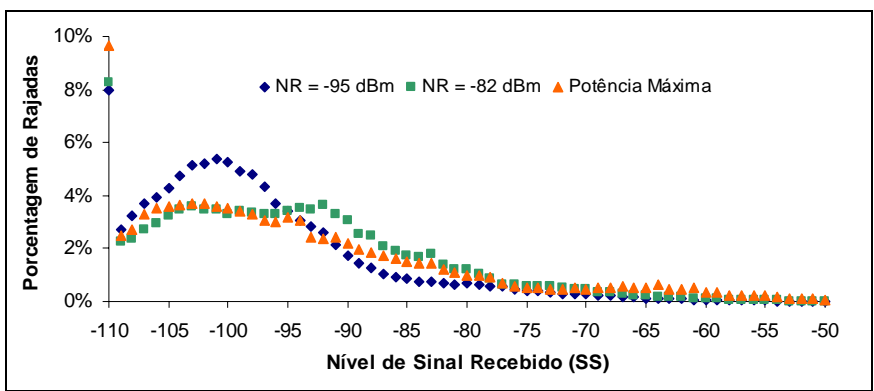

Fig. 3. Relação entre a porcentagem de rajadas e a intensidade de sinal recebido pela ERB da célula $\mathrm{A}$ antes e depois da alteração no controle de potência da EM.

Nota-se que com $N R=-82 \mathrm{dBm}$ e sem o PC houve um aumento no nível recebido acima de $-94 \mathrm{dBm}$, sendo que acima de $-77 \mathrm{dBm}$ os níveis são praticamente iguais nos três casos. A Tabela 4 reproduz a Tabela 3 comparando as três alterações com seus respectivos períodos.

TABELA 4. COMPORTAMENTO DA INTERFACE AÉREA DA CÉLULA A APÓS OS TRÊS AJUSTES DE POTÊNCIA.

\begin{tabular}{|c|c|c|c|c|c|c|}
\hline DATA & $\begin{array}{c}\text { SSUP } \\
<-94 \mathrm{dBm} \\
(\%)\end{array}$ & $\begin{array}{c}<-94 \mathrm{dBm} \\
(\%)\end{array}$ & $\begin{array}{c}\text { PLAVG } \\
\text { UP (dB) }\end{array}$ & $\begin{array}{c}\text { PLAVG } \\
\text { DL (dB) }\end{array}$ & $\begin{array}{c}\text { RXQUAL } \\
\text { UP } \\
>3(\%)\end{array}$ & $\begin{array}{c}\text { RXQUAL } \\
\text { DL } \\
>3(\%)\end{array}$ \\
\hline 1 a $15 / 09 / 07$ & 69,56 & 26,85 & 125,48 & 128,48 & 8,39 & 5,7 \\
\hline 16 a $30 / 09 / 07$ & 53,38 & 21,06 & 122,66 & 125,61 & 9,03 & 4,73 \\
\hline 1 a $15 / 11 / 07$ & 55,12 & 22,25 & 125,21 & 127,44 & 9,98 & 5,22 \\
\hline
\end{tabular}

Por fim, será analisado o comportamento da TQC com os três ajustes do PC. A Tabela 5 apresenta a TQC e as principais causas de QC. Com o ajuste do NR para $-82 \mathrm{dBm}$, houve novamente uma redução na TQC, passando de 1,77\%, quinze dias antes da alteração, para 1,44\%, quinze dias após. 
Por outro lado, houve aumento da TQC quando o PC foi desativado.

TABELA 5. COMPARAÇÃO DA TQC COM OS TRÊS AJUSTES DE POTÊNCIA NA CÉLULA A

\begin{tabular}{|c|c|c|c|c|c|c|c|c|c|c|}
\hline DATA & $\begin{array}{c}\text { TQC } \\
(\%)\end{array}$ & $\begin{array}{c}\text { QSB } \\
(\%)\end{array}$ & $\begin{array}{c}\text { QSU } \\
(\%)\end{array}$ & $\begin{array}{c}\text { QSD } \\
(\%)\end{array}$ & $\begin{array}{c}\text { QQB } \\
(\%)\end{array}$ & $\begin{array}{c}\text { QQU } \\
(\%)\end{array}$ & $\begin{array}{c}\text { QQD } \\
(\%)\end{array}$ & $\begin{array}{c}\text { QDE } \\
(\%)\end{array}$ & $\begin{array}{c}\text { QPR } \\
(\%)\end{array}$ & $\begin{array}{c}\text { QOC } \\
(\%)\end{array}$ \\
\hline $\begin{array}{c}1 \mathrm{a} \\
15 / 09 / 07\end{array}$ & 1,77 & $\begin{array}{c}29,2 \\
2\end{array}$ & $\begin{array}{c}29,8 \\
7\end{array}$ & 3,03 & 0,22 & 0,43 & $\begin{array}{c}15,3 \\
7\end{array}$ & 0,43 & $\begin{array}{c}19,4 \\
8\end{array}$ & 1,95 \\
\hline $\begin{array}{c}16 \mathrm{a} \\
30 / 09 / 07\end{array}$ & 1,44 & $\begin{array}{c}31,6 \\
2\end{array}$ & $\begin{array}{c}29,9 \\
6\end{array}$ & 2,76 & 0,18 & 1,84 & $\begin{array}{c}10,2 \\
9\end{array}$ & 1,84 & 19,3 & 2,21 \\
\hline $\begin{array}{c}1 \mathrm{a} \\
15 / 11 / 07\end{array}$ & 1,61 & $\begin{array}{c}29,3 \\
4\end{array}$ & $\begin{array}{c}34,7 \\
5\end{array}$ & 3,47 & 0,19 & 0,39 & $\begin{array}{c}10,4 \\
2\end{array}$ & 0,39 & $\begin{array}{c}18,1 \\
5\end{array}$ & 2,9 \\
\hline
\end{tabular}

\section{CONCLUSÕES}

O estudo dos indicadores de desempenho de uma rede é muito importante para as operadoras, pois garante a qualidade da rede celular, a satisfação dos assinantes da rede e a redução dos investimentos em operação da rede, por meio da economia com instalação de novos equipamentos e com deslocamento de pessoal técnico.

Com base nos dados estatísticos de tráfego de rede GSM, foi possível ajustar alguns parâmetros de cobertura de uma célula, possibilitando reduzir a TQC de 8,96\% para 1,44\% e obtendo uma redução no número global de handovers perdidos, passando de $28,8 \%$ para $1,04 \%$.

\section{REFERÊNCIAS}

[1] Halonen, T., Romero, J., Melero J., GSM, GPRS, and Edge Performance: Evolution towards 3G/UMTS, 2nd ed. West Sussex: John Wiley \& Sons Ltd. 2003.

[2] Kyriazakos, S., Papaoulakis, N., Nikitopoulos, D., Gkroustiotis, E., Kechagias, C., Karambalis, C., Karetsos, G., "A Comprehensive Study and Performance Evaluation of Operational GSM and GPRS Systems under Varying Traffic Conditions”, IST Mobile Summit, junho 2002.

[3] Boulmalf, M., Akhtar, S., "Performance evolution of operational GSM's Air Interface”, College of Information Techonology, Al-Ain, 2002, disponível http://www.scs.org/scsarchive/getDoc.cfm?id=2090.

[4] Markopoulos, A. Kyriazakos, S. Tsagkaris, K. Sykas, E.D., "Performance of cellular networks and mobile location-driven handover algorithms”, IEEE 59th Vehicular Technology Conference, vol. 4, pp. 2430- 2436, maio 2004.

[5] Ivanov K., Ball C.F., Miillner R., Winkler H., Perl R., Kremnitzer K., "Breaking Through AMR Voice Capacity Limits due to Dropped Calls by Control Channel Improvements in GERAN Networks", IEEE 16th International Symposium on Personal, Indoor and Mobile Radio Communications, 2005.

[6] Drozdy, G., Niemella, J., Valimaki, J., Rosenberg, J., Hara, V., "Study of GSM system performance by a GSM network computer simulator”, IEEE International Conference on Selected Topics in Wireless Communications, pp. 336-339, junho 1992.

[7] Toftegaard Nielsen, T., Wigard, J., Skjaerris, S., Jensen, C.O., Elling, J., "Enhancing Network Quality using Baseband Frequency Hopping, Downlink Power Control and DTX in a Live GSM Network”, IEEE $9^{\text {th }}$ International Symposium on Personal, Indoor and Mobile Radio Communications, vol. 2, pp. 905-909, setembro 1998.

[8] Bregni, S. Barbieri, L., "Experimental evaluation of the impact of network frequency synchronization on GSM quality of service during handover", IEEE Global Telecommunications Conference, GLOBECOM '03, vol. 6, pp. 3457-3461, dezembro 2003.
[9] Zhang, N., Holtzman, J. M., “Analysis of Handoff Algorithms Using both Absolute and Relative Measurements”, IEEE Transactions on Vehicular Technology, vol. 45, pp. 174-179, fevereiro 1996.

[10] ERICSSON inc., User Description, Locating. 2004.

[11] Eberspächer, J., Hans-Jörg, V., Bettstetter, C., GSM Switching, Services and Protocols, 2nd ed. West Sussex: John Wiley \& Sons Ltd. 2001. 